\title{
On Chinese Culture Teaching of Chinese as a Foreign Language
}

\author{
Sun Huiling \\ The Silk Road School of art \\ Weinan normal University \\ Weinan, China \\ Wszn30@126.com
}

\begin{abstract}
There are cultural requirements for all five levels in "International curriculum for Chinese language education", which provides a basis for cultural teaching in teaching Chinese as a foreign language, and basically solves the problem of "what to teach". What is more practical is that "How to teach", "who will teach". Ultimately, the most important thing is to cultivate what kind of Chinese teachers. A good Chinese teacher should have a keen awareness of cultural self-consciousness and introspection; meanwhile he should have the ability to keep learning. So in the practice of teaching, he will not impart the Chinese language and culture mechanically, and will not blindly promote Chinese culture. He can organically combine language and culture with an open and equal attitude. Naturally, students are influenced by the silent way, imperceptibly students can actually perceive and understand Chinese culture, and deeply attracted to Chinese culture, and will also produce more strong desire to learn Chinese. Such a teacher will also become an outstanding Chinese teacher.
\end{abstract}

Keywords-Chinese as a foreign language; International curriculum for Chinese language education; Chinese culture teaching; Chinese international teachers

\section{INTRODUCTION}

The cultural teaching research of Chinese as a foreign language has gone through thirty years. In these years, various discussions about the relationship between culture and language, the classification of Chinese culture, and the publication of various cultural materials, showed the necessity and importance of cultural teaching. And these materials are detailed in "20 years review of Chinese culture study of Chinese as a foreign language" [1] and "Review on the study of cultural teaching in teaching Chinese as a foreign language in the last thirty years". [2]

On the basis of the above research, we will discuss the cultural teaching of Chinese as a foreign language in depth. The acquisition of any language is ultimately inseparable from the understanding of its culture, and without the understanding of cultural the learning of language will become a rootless wood, and the water of passivity. Pascal Melbourne once said: "foreign language teaching is not just a language acquisition, but it includes profound cultural connotations, the language faithfully reflects the whole history and culture of a nation, and fully stores the whole information of the culture, which carries the concept of human beings and conveys specific cultural connotations."'[3] Therefore, in the process of teaching Chinese as a foreign language, we should explain and impart knowledge of Chinese language and train Chinese language skills from the perspective of culture, we should also explain Chinese culture from the perspective of language, so that the world can better understand Chinese culture.

\section{THE SIGNIFICANCE OF THE PUBLICATION OF THE INTERNATIONAL CURRICULUM FOR CHINESE LANGUAGE EDUCATION}

From this point of view, the publication of "International curriculum for Chinese language education" is of great significance; especially it has a cultural requirement for every level of content. [4] Of course, the cultural provisions of International curriculum for Chinese language education also have a discussion, but it makes the culture teaching of Chinese as a foreign language has the basis. It is an essential element for training the learners to have international vision and multicultural awareness, and to use language more appropriately. The "International curriculum for Chinese language education" is based on the age characteristics and cognitive ability of students, and gradually expand the content and scope of cultural knowledge, so as to help students to broaden their horizons, but also enable learners to understand the status and role of Chinese culture in world culture, and the contribution to the culture of the world. The principle it embodies is, in general, from easy to difficult, from shallow to deep, from phenomenon to essence.

"International curriculum for Chinese language education" basically solves the problem of "what to teach" in teaching Chinese as a foreign language, and the next one is the question of "how to teach", which is a more difficult issue to deal with. Taking the first cultural theme "custom etiquette" of the first level of the "International curriculum for Chinese language education" as an example, there are three learning tasks: one is to understand the Chinese people's meeting etiquette, and the other is to understand the Chinese cultural meanings given to color by Chinese people , and The third is to understand the cultural meanings given to numbers by Chinese people.

The first task is simple. The Chinese people now meet to greet each other with "hello" and shake hands in a grand 
occasion. But in the past, Chinese people often asked, "did you eat?" Behind, the meeting etiquette implied a lot of Chinese traditional culture, China is a agricultural country since ancient times, and it has a large population, thousands of years a lot of people do not have enough food to eat, so the Chinese pay special attention to eat, also pay attention to the diet culture very much, so now the Chinese food is very rich and very delicate and exquisite. The second task, the Chinese color, knowledge points is not difficult to understand. However, it is not easy to make clear why Chinese people like red and yellow. This is because most of the early civilizations in the world are worshiping the red color of the sun, flames and blood. Later, the red color in China carries the "revolutionary memory" The color of the common faith of the proletariat. Yellow is associated with rice, wheat, corn and land, mainly in agricultural society. Later, yellow has become the exclusive color of the emperor, people cannot use it. Now these two colors have almost become China's representative color. The third task of the figures, made 88 notes made a fortune, 66 indicates a smooth, 99 homonyms for a long time in modern China. Another 7 in the Chinese culture is also a very important figure, this is in line with the world culture and can communicate with each other, such as seven days a week, "Snow White" over seven mountains, across seven rivers, to see seven Dwarfs and so on. In fact, the best cultures of all the nations in the world are all connected at the source, and they are shared by all mankind. All of these will attract students deeply, so that students can better understand Chinese culture and have a strong passion for learning Chinese culture.

\section{FURTHER THOUGHTS ON CHINESE CULTURE TEACHING}

In the whole ,there are five levels, twenty-eight themes and sixty-eight learning tasks in the "International curriculum for Chinese language education "about culture, which are not easy to accomplish. And it is more difficult to teach the true meaning of Chinese culture and to attract students. And the "International curriculum for Chinese language education "is only an example, and there should be a lot of Chinese cultural themes that are not reflected in this form. Therefore, in the actual culture teaching, how to timely and appropriately grasp the depth and difficulty of culture teaching are all need to be seriously considered by teachers. And all of these need to stand on the other side, namely, the position of students, to prepare teaching methods. That is, what is the cultural needs and cultural interest of the foreign learners of Chinese? What kind of cultural needs we can meet, what kind of cultural interest we can meet, and what kind of needs and interests we can't be met. In order to meet the needs and interests of foreign learners of Chinese, we can also guide the cultural needs and cultural interests. At the same time, we can also take a look at what kind of Chinese culture we really have, and what kind of Chinese culture we need to convey, and what kind of Chinese culture we should inherit and cultivate ourselves.

In the final analysis, teaching Chinese as a foreign language is not only a question of "what to teach" or "how to teach", but more importantly, "who will teach", or what kind of foreign language teachers we should cultivate to fulfill this mission. It requires not only the mandarin level qualified, have the corresponding Chinese knowledge, master the necessary
China cultural knowledge and skills, good communication skills and necessary language skills and good occupation morality, occupation accomplishment. It should have other higher standards.

\section{CULTURAL TEACHING DEMANDS HIGHER REQUIREMENTS FOR INTERNATIONAL CHINESE TEACHERS}

In December 12, 2012, The NOCFL (China National Office for Teaching Chinese as a Foreign Language ) issued the "international standard for Chinese teachers". The "Standard" Consists of five parts: "Chinese Teaching Fundamentals", "Chinese Teaching Methods", "Teaching Organization and Class Management", "Chinese Culture and Intercultural Communication" and "Professional Ethics and Professional Development",which build the basic framework of knowledge, ability and quality of international Chinese language teachers, and formed a relatively complete and scientific system of standards. It should be said that the new standard is relatively high for international Chinese teachers, and there are not many international Chinese teachers who are fully qualified. But looking at the future of international Chinese education, such standards are still not enough. It should be based on this standard to increase the requirement for the soft power of international Chinese teachers.

What is the soft power of the international Chinese teachers? The author thinks that it is the soft power of the teachers of the international Chinese only to have the consciousness of self-examination and continuous learning ability. Even such a person can't fully meet the requirements of the new standard temporarily. If he has a keen sense of cultural self-consciousness and he has the ability of continuous learning, he will become an excellent Chinese international teacher. So in the practice of teaching, he will not impart the Chinese language and culture mechanically, and will not blindly promote Chinese culture. With an open and equal attitude, he can organically combine the teaching of language and culture. Naturally, students are influenced by the silent way of moistening things, imperceptibly, so that students can actually perceive and understand and sympathize with Chinese culture, and deeply attracted to Chinese culture, and will also produce more strong desire and motivation to learn Chinese. These are just like what Mr. Lu Jianming have said: "culture education in Chinese teaching should study hard from this aspect, instead of offering some culture lessons like that, and teaching some cultural skills. At present this practice is only a fickle move... Chinese teachers are the ambassadors of Chinese culture, which are the windows and mirrors of Chinese culture.'[5] In fact, the fundamental significance of teaching Chinese and culture by Chinese teachers is to try to communicate different societies, different countries, and different cultures. Among these different ideology, habits and customs and cultural traditions, bridges are built up to communicate and understand. This process can be compared to those that recreate human "Babel", and those who can do so will become the best international Chinese teachers.

Attached: An example of Chinese cultural themes and cultural tasks in "International curriculum for Chinese language education" 


\section{Class A}

Custom and Rites: 1. Understand the etiquette of the Chinese people2. Understand the cultural meaning of the Chinese people's color3. Understand the cultural implications of Chinese figures

Family appellation: 1. Understand the names of Chinese people2. Understand the family concept of China

Chinese Zodiac: 1. Understand the name and order of the twelve Chinese Zodiac2. Understand the China legend about the zodiac

Class B

Music and dance and painting: 1 . Understand the unique and classification of Chinese music 2. Understand the national dance of China3. Understand Chinese painting art and landscape painting

Sports: 1 . Understand and identify the form of martial arts in Taijiquan2. Understand popular sports in China

Traffic: 1. Familiar with China's daily transportation2. Understand the status of bicycles and the status of cars in China

Mass media: 1. Understand the media forms such as radio, television, newspapers and magazines.2. The names of authoritative newspapers and magazines, radio and television stations

\section{Class C}

Geography: 1. Familiar with the name of China's neighbors 2 . Understand the geographical location of the main neighbors and China

Architecture: 1. Understand the name and basic characteristics of Chinese traditional architecture

Education: 1. Understand the setting up of Chinese Schools2. Understand and familiarity with the curriculum of Chinese Schools

Custom and Rites: 1. Understand the way China presents or accepts gifts2. Understand the traditional customs of Chinese people for their birthday3. Understand the courtesy of Chinese people when they say goodbye

Music and dance and painting: 1. Understand and appreciate the famous Chinese classical music and national music2. Understand and appreciate the famous Chinese national dance3. Understand the famous painters in Chinese history and appreciate their works

\section{Class D}

Geography: 1. Understand the topographic features of China2. Understand the geographical features of China3. Understand the name of the famous mountain and river in China

Theatre: 1. Understand the types of Chinese drama2. Understand the names of common tracks and simple story outline
Festival: 1. a simple understanding of the legend of the Spring Festival, the Dragon Boat Festival and the Mid Autumn Festival

Traffic: 1. can understand the bus stop in China2. Understand the way of expressing the train traffic in China

Customs: 1.Understand the Spring Festival is the most important traditional festival and its customs and habits2. Understanding the Dragon Boat Festival is an important folk festival and its customs and habits3. Understanding the Mid Autumn Festival is the reunion festival and its customs and habits

Music and dance painting: 1. Understand Chinese music further and learn simple folk songs and pop songs2. Understand the common musical instruments and recognize the sound of music3. Understand the popular style of dance in modern China4. Understand the artistic features of Chinese painting

Sports: 1. Understand the status of sports in China and the country in the world2. Know Liu Xiang, Yao Ming and other international sports stars

Mass media: 1. Understand the characteristics of domain names commonly used in China Network2. Try to use the Chinese network to find data

Class E

Climate geography: 1. Understand the diversity and characteristics of China's climate2. Understand the administrative division of China3. Know the name of the major city and its location in China

History: 1. Understand the important historical stage of Chinese history and the dynasty 2. Understand the major historical events in Chinese history3. Understand the famous historical figures in Chinese history

Contemporary China: 1 . Understand the basic situation of contemporary China's finance 2 . Understand the basic characteristics of China's economic development3. Understand the basic status of China's rural areas4. Understanding of the regional differences and the general situation of urban and rural differences in China

Literary drama: 1 . Know the name of the four famous Chinese books and understand the outline of the story2. Know Chinese contemporary famous writers and understand some stories3. Understand the history and development of Beijing Opera

Tourism: 1.Know the name of the famous tourist attractions in China and understand the content of its landscape

Customs: 1. Understand the customs of famous scenic spots in China 2. Understand the Chinese tradition of respecting the old and love young3. Understand the history and tradition of inferiority of Chinese men and advocate the status of equality4. Understand the current golden week and its social impact 
Diet: 1. Learn Chinese cooking methods2. Understand the Chinese diet

Property: 1. Understand and learn the name and basic characteristics of several common Chinese herbs2. Understand China's famous tea and origin3. Learn several common Chinese wines.

\section{CONCLUSION}

Culture teaching is the core content of teaching Chinese as a foreign language, and it is also the most difficult content. "International curriculum for Chinese language education" published by The NOCFL has given detailed classification and requirement for Chinese cultural themes and cultural tasks, which is very meaningful in culture teaching. But the actual Chinese culture is not only the content listed in the curriculum, but also the richer content and deeper connotation. This has raised higher requirements for international Chinese teachers. The NOCFL also issued the "international standard for Chinese teachers". It provides a guarantee for the selection of suitable international Chinese teachers. However, due to the extensive and profound Chinese culture itself and because of the complexity of cultural teaching, based on these rigid standards, there should also be requirements for the soft power of international Chinese teachers. In practice teaching, the teacher becomes the image ambassador of Chinese culture, so as to Build bridges of communicate and understand among different ideology, custom and culture tradition, and rebuild human " Tower of Babel".

In short, culture teaching in teaching Chinese as a foreign language is very important and hard to grasp. This paper only makes some researches and discussions from two aspects, namely, the cultural theme and cultural tasks, as well as the standards of international Chinese teachers. But there is still a lack of specific data in the teaching practice. This will require the Chinese international teachers to explore the experience in practice and constantly sum up experiences and lessons learned. Relevant scholars also need to make in-depth theoretical discussions and researches on this issue.

\section{REFERENCES}

[1] Qi Hua. 20 years review of Chinese culture study of Chinese as a foreign language [J].2003 Journal of Beijing Normal University, 6:104-109.

[2] Li Xiubin, Zang Shengnan. Review on the study of cultural teaching in teaching Chinese as a foreign language in the last thirty years [J] .Education and teaching research in.2013, 7:73-77.

[3] Pascal Melbourne. Introduction to linguistics. Selection of famous western linguistic works [M].Beijing: People's University Publication House, 1988.

[4] China National Office for Teaching Chinese as Foreign Language.International curriculum for Chinese language education. Beijing: Foreign Language Teaching and Research Press, 2010.

[5] Lu Jianming. Localization of Chinese international education major [J]. Language teaching and research.2014, 2:11-16. 